\title{
Randomised study of the influence of non-steroidal anti-inflammatory drugs on the treatment of peptic ulcer in patients with rheumatic disease
}

\author{
C MANNICHE, A MALCHOW-MøLLER, J R ANDERSEN, C PEDERSEN, \\ T M HANSEN, P JESS, L HELLEBERG, S N RASMUSSEN, U TAGE-JENSEN, \\ AND S E NIELSEN \\ From the Departments of Medicine B and Rheumatology, Frederiksborg Central Hospital, Hillerød; \\ Department of Medicine, Divisions of Gastroenterology and Rheumatology, Hvidovre Hospital, University of \\ Copenhagen; Departments of Surgery F and Rheumatology, Bispebjerg Hospital, University of Copenhagen; \\ Departments of Medicine F and Rheumatology, Glostrup Hospital, University of Copenhagen, Denmark
}

SUMmARY Sixty-seven patients with rheumatic disease, treated with non-steroidal antiinflammatory drugs (NSAIDs), entered a controlled trial with a diagnosis of duodenal $(n=51)$, gastric $(n=14)$, or gastric and duodenal $(n=2)$ ulcers. The main objectives of the study were a comparison of ranitidine and sucralfate in ulcer treatment, and to observe the influence of continued NSAID administration during peptic ulcer therapy. Ulcers healed within nine weeks in 52 patients. The mean healing time was similar in 27 patients given ranitidine $150 \mathrm{mg}$ bd (4.9 weeks) and 25 patients given sucralfate $1 \mathrm{~g}$ qid (4.6 weeks). In patients with unhealed ulcers after nine weeks of treatment, healing was obtained in seven after further therapy for 3-9 weeks. Of the 30 patients who continued NSAIDs during treatment with either ranitidine or sucralfate, 23 ulcers healed (mean healing time: 5.0 weeks). Of 32 patients in whom NSAIDs were stopped, ulcer healing was documented in 29 (mean healing time: 4.6 weeks). The difference in healing rates was not statistically significant $(\mathrm{p}>0 \cdot 10)$. The outcome of ulcer treatment did not differ in patients with rheumatoid arthritis and patients suffering from osteoarthritis. During a 12 month follow up 14 symptomatic ulcer recurrences were recorded.

Mucosal lesions of the stomach or duodenum are seen frequently in patients taking NSAIDs. The incidence of peptic ulcer has been reported to lie between $17 \%$ and $31 \%^{1-3}$ and elderly patients may be especially susceptible to NSAID associated peptic ulcer perforation. ${ }^{4} \mathrm{~A}$ variety of problems, such as lack of control groups, few prospective studies, multidrug therapy, etc, make it very difficult to reach firm conclusions as to the ulcerogenicity of NSAIDs $^{5-6}$ except for unbuffered aspirin, which is considered ulcerogenic. ${ }^{57}$ In a recent paper, however, it was reported that bleeding complications

Address for correspondence: Axel Malchow-Møller, MD, Medical Dept P2132. Division of Gastroenterology, Rigshospitalet, 9 Blegdamsvey, DK-2100. Copenhagen $\emptyset$. Denmark.

Received for publication 13 June 1986. from peptic ulcers in patients over 60 years was correlated with use of non-aspirin NSAIDs. ${ }^{8}$ The possible influence of NSAIDs on the ulcer healing process has been evaluated in only a few, mainly retrospective studies including a limited number of patients. ${ }^{211}$

This study compares the effects of ranitidine or sucralfate on the healing of peptic ulcer in patients with rheumatic disease, half of whom were randomised to continue on NSAID, while the remainder were given alternative analgesic therapy. After ulcer treatment patients were followed up for 12 months.

\section{Methods}

PATIENTS

Sixty seven consecutive patients from the four participating departments were included, 38 with 
Table 1 Inclusion and exclusion criteria

Inclusion criteria
Rheumatic disorder continuously treated with NSAID
Dyspepsia and endoscopically verified gastric or duodenal ulcer
Ulcer diameter $>3 \mathrm{~mm}$
Exclusion criteria
Informed consent not obtained
Operation for peptic ulcer within the last 3 months
Pregnancy, lactation
Severe concomitant disease
Treatment with prednisolone $>15 \mathrm{mg} /$ day
Ulcer perforation or other complications to ulcer disease
Patient's wish to withdraw

definite or classical rheumatoid arthritis according to ARA criteria, 24 with osteoarthritis based on clinical and radiological findings and five patients with other diagnoses (degenerative lumbar disc disease three, ankylosing spondylitis one, psoriatic arthritis one). The mean pretrial duration of NSAID treatment was 5.2 years (range $0.3-20$ ) for patients with rheumatoid arthritis and 5.5 years (range $0.1-15$ ) for patients with osteoarthritis or other rheumatic disorders. Twenty six patients were smokers. Inclusion and exclusion criteria are shown in Table 1 . The various NSAIDs administered at the time of entry into the study are listed in Table 2 . Five patients received penicillamine, $375-625 \mathrm{mg} / \mathrm{day}$, and nine patients prednisolone, $15 \mathrm{mg} /$ day or less.

After endoscopic diagnosis, patients were allocated to one of four treatment regimens according to a block randomisation procedure: (a) Ranitidine, $150 \mathrm{mg}$ bd; continued administration of NSAID. (b) Sucralfate, $1 \mathrm{~g}$ qid; continued administration of NSAID. (c) Ranitidine $150 \mathrm{mg}$ bd; withdrawal of NSAID. (d) Sucralfate $1 \mathrm{~g}$ qid; withdrawal of NSAID. (Figure.)

Antacids were allowed but not recommended; any antacid consumption was noted in the patient diary. Level of discomfort from ulcer symptoms was

Table 2 List of NSAID administered in the rheumatic disease patients at time of entry into study

\begin{tabular}{lcc}
\hline Drug & Dose $(m g /$ day $)$ & Patients $(n)$ \\
\hline Acetylsalicylic acid & $2000-4000$ & 5 \\
Azapropazone & $600-900$ & 5 \\
Diclofenac & $100-200$ & 10 \\
Fenbufen & 900 & 1 \\
Fenoprofen & 1800 & 1 \\
Ibuprofen & $800-1600$ & 15 \\
Indomethacin & $100-150$ & 9 \\
Ketoprofen & 100 & 1 \\
Naproxen & $500-1000$ & 10 \\
Piroxicam & $10-20$ & 9 \\
Sulindac & 300 & 1 \\
\hline
\end{tabular}

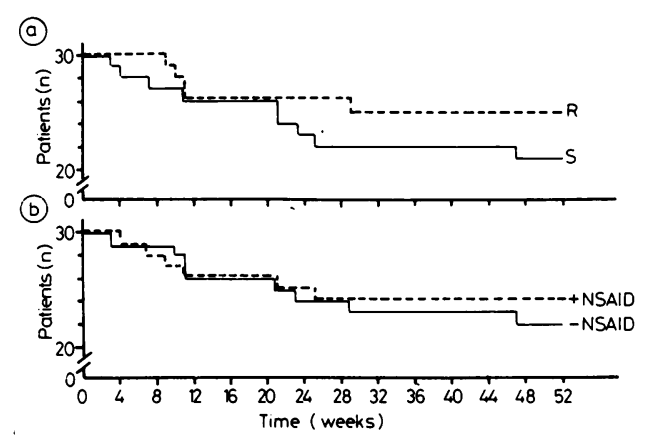

Figure Recurrences of peptic ulcer in 60 rheumatic disease patients according to randomisation at time of entry into study. (a) shows relapses in patients randomised to ranitidine $(R)$ or sucralfate $(S) ;(b)$ shows relapses in patients randomised to continued administration of NSAID or withdrawal of NSAID during ulcer treatment. The two patients who died during follow up are not shown in this Figure.

recorded daily on a $10 \mathrm{~cm}$ long visual analogue scale $(0=$ no discomfort; $10=$ very severe discomfort $)$. Three patients with severe arthritic pain at night received morphine analogues for a limited period of time; two of them had occasional treatment with opiates before inclusion in the trial.

Ulcer healing was recorded endoscopically every three weeks. The endoscopist had no knowledge of the drugs being taken. If an ulcer had not healed after nine weeks, the treatment was changed to the other antiulcer drug, but NSAID treatment or nontreatment was not changed.

After ulcer healing the patients were followed for 12 months, attending the rheumatological outpatients clinics at regular intervals. Patients in whom NSAIDs had been stopped were free to start such treatment. Patients developing dyspepsia during the follow up period were re-endoscoped to confirm the diagnosis.

DURATION OF STUDY AND STATISTICS

The study was planned to include 80 patients. For practical reasons, however, entry was closed after two years when 67 patients had been entered. Chisquare test with Yates's correction for continuity was used. A 5\% significance level was chosen.

ETHICAL CONSIDERATIONS

We did not think it justified to include a placebotreated group because of the many effective and well tolerated antiulcer drugs available today. ${ }^{12}$ The investigation was approved by the regional ethical committees, and all patients gave their informed consent. 


\section{Results}

Of the 67 patients recruited to the study, 51 had a duodenal or prepyloric ulcer, 14 had a gastric ulcer, and two had both duodenal and gastric ulcers. Eleven duodenal ulcers (22\%) and five gastric ulcers (36\%) were of $\geqslant 10 \mathrm{~mm}$ diameter; these were equally distributed in the four treatment groups. Five patients were excluded during the first three weeks of treatment because of lack of cooperation or claims of adverse reactions without any clinical findings (two), cerebral haemorrhage (one), poor general condition (one), and minor but persistent gastrointestinal bleeding (one).

Sixty two patients were available for analysis: 34 with rheumatoid arthritis ( 15 men; median age 67 (range 43-87) years) and 28 with non-rheumatoid arthritis (24 with osteoarthritis and four with other rheumatic diseases; 12 men; median age 71 (range 35-85) years).

Table 3 shows that the proportion of healed ulcers and the mean healing time were similar in patients given either ranitidine or sucralfate. In 10 patients with persistent ulcer after nine weeks of treatment, continued therapy with the alternative anti-ulcer drug resulted in healing in seven patients after a further three to nine weeks of treatment.

Table 4 shows the results of ulcer treatment in patients who continued on a NSAID in comparison with patients in whom the NSAID was discontinued. There were no differences in the healing rates and the mean healing time between the various subgroups. The $14 \%$ difference between NSAID takers and nontakers in overall healing rate is not statistically significant $\left(\chi^{2}=2 \cdot 23 ; p>0 \cdot 10\right)$.

Median values for the visual analogue scale of ulcer symptoms were $2 \cdot 8$ (range $0-10$ ) at the time of entry; 1.4 (range $0-8$ ) after one week of treatment, and 0.7 (range 0-6) after three weeks. Very few patients had dyspeptic complaints after the initial three weeks of ulcer therapy. Thirty patients, with an equal representation in the treatment groups, reported antacid use equivalent to a neutralising capacity of $15-50$ $\mathrm{mmol} /$ day ( 24 patients) and from $50-75 \mathrm{mmol} /$ day in the remainder. Antacid consumption was unusual after the first three weeks of ulcer therapy.
During the 12 months follow up 14 of 32 patients randomised to withdrawal of NSAIDs, resumed this treatment whereas 15 of 30 patients randomised to continued NSAIDs gave up the same. Symptomatic ulcer recurrences were documented in 14 patients (eight smokers), nine of whom took NSAIDs at the time of relapse. The recurrences were evenly distributed in the four randomisation groups (Figure). Ulcer rehealing was shown endoscopically in 10 of these patients after three to six weeks of treatment with either of the two ulcer regimens. Two patients died during the follow up, but death could not be associated with complications of the peptic ulcer disease.

There were very few and non-specific complaints of adverse reactions possibly related to ranitidine or sucralfate. Routine laboratory screening tests did not show any abnormalities, except for a transient rise in S-creatinine in one patient.

\section{Discussion}

Withdrawal of salicylates and other NSAIDs is generally recommended to a patient with a peptic ulcer. This trial has shown that ulcer treatment can be accomplished in spite of continuous administration of NSAIDs. The patients received a broad spectrum of NSAIDs and five were given aspirin, which is likely to cause more mucosal damage than the other NSAIDs. ${ }^{13}$ The conclusions of our study would be unchanged, even if the five aspirin takers had been excluded from the analyses.

Sucralfate, a non-absorbable 'cytoprotective drug' with proven efficacy in the treatment of peptic ulcer ${ }^{14}$ was compared with ranitidine, a potent $\mathrm{H}_{2}$-receptor blocker. ${ }^{\text {is }}$ Both drugs can be expected to heal $85-90 \%$ of peptic ulcers after eight weeks of treatment. The randomisation procedure guaranteed an even distribution of patients in the four treatment groups as well as a balanced representation of the two major rheumatic disorders, rheumatoid arthritis and osteoarthritis, within these groups. It is therefore permissible, in later calculations, to combine the diagnostic and/or treatment groups as appropriate.

Virtually, the same healing rate and mean healing time were found for ranitidine and sucralfate. The Table 3 Results of peptic ulcer treatment with ranitidine or sucralfate for up to nine weeks in 62 patients with rheumatic disease.

\begin{tabular}{|c|c|c|c|c|c|c|}
\hline & \multicolumn{3}{|l|}{ Ranitidine } & \multicolumn{3}{|l|}{ Sucralfate } \\
\hline & Patients ( $n$ ) & Healed (n) & $\begin{array}{l}\text { Mean time to } \\
\text { healing (weeks) }\end{array}$ & Patients (n) & Healed (n) & $\begin{array}{l}\text { Mean time to } \\
\text { healing (weeks) }\end{array}$ \\
\hline $\mathrm{RA}$ & 18 & $15(83 \%)$ & $4 \cdot 6$ & 16 & $12(75 \%)$ & $4 \cdot 0$ \\
\hline $\mathrm{OA}$ & 14 & $12(86 \%)$ & $5 \cdot 3$ & 14 & $13(93 \%)$ & $5 \cdot 1$ \\
\hline Total & 32 & $27(84 \%)$ & 4.9 & 30) & $25(83 \%)$ & $4 \cdot 6$ \\
\hline
\end{tabular}

RA: Rhcumatoid arthritis; OA: Ostcoarthritis. 
Table 4 Influence of NSAID on peptic ulcer treatment in 62 patients with rheumatic disease. No statistically significant differences between maingroups or subgroups.

\begin{tabular}{|c|c|c|c|c|c|c|c|c|}
\hline & \multicolumn{4}{|c|}{ Continued NSAID } & \multicolumn{4}{|c|}{ Withdrawal of NSAID } \\
\hline & \multicolumn{2}{|c|}{ Ratio of healed ulcers } & \multicolumn{2}{|c|}{$\begin{array}{l}\text { Meantime to healing } \\
\text { (weeks) }\end{array}$} & \multicolumn{2}{|c|}{ Ratio of healed ulcers } & \multicolumn{2}{|c|}{$\begin{array}{l}\text { Meantime to healing } \\
\text { (weeks) }\end{array}$} \\
\hline & $G U$ & $D U$ & $G U$ & $D U$ & $G U$ & $D U$ & $G U$ & $D U$ \\
\hline Small ulcers $($ diam $<1.0 \mathrm{~cm})$ & $1 / 2(50 \%)$ & $14 / 15(93 \%)$ & $9 \cdot()$ & $4 \cdot 0$ & $3 / 3(100 \%)$ & $12 / 12(100 \%)$ & $3 \cdot 0$ & $3 \cdot 0$ \\
\hline Large ulcers : diam $\geqslant 1 \cdot() \mathrm{cm})$ & $2 / 4(50 \%)$ & $6 / 9(67 \%)$ & $7 \cdot 5$ & $6 \cdot 0$ & $3 / 4(75 \%)$ & $11 / 13(85 \%)$ & $8 \cdot()$ & $5 \cdot 7$ \\
\hline Subtotal & $3 / 6(50 \%)$ & $20 / 24(83 \%)$ & & & $6 / 7(86 \%)$ & $23 / 25(92 \%)$ & & \\
\hline Total: GU+DU & $23 / 30(77 \%)$ & & $5 \cdot()$ & & $29 / 32(91 \%)$ & & $4 \cdot 6$ & \\
\hline
\end{tabular}

GU: Gastric ulcer; DU: Duodenal ulcer.

proportion of healed ulcers rose from $31 / 62(50 \%)$ at three weeks to $52 / 62(84 \%)$ at nine weeks. This corresponds with results from studies involving nonrheumatic patients. Non-steroidal anti-inflammatory drug takers with gastric ulcers tended to heal more slowly, or not at all within nine weeks, but seven of 10 persistent ulcers did heal after a total of 12-18 weeks of treatment.

Asymptomatic ulcer recurrences were not registered. This is in accordance with the entry criteria of dyspepsia. Excluding the two patients who died during follow-up, the recurrence rate was $0 \cdot 23$ (95\% confidence limits: $0 \cdot 13-0 \cdot 36$ ). This is probably a minimum estimate as can be judged from studies in non-rheumatic patients ${ }^{16}$ which, however, often include asymptomatic ulcers found at endoscopy at fixed intervals during the follow-up period.

From the results of this study, we suggest that NSAIDs should not be stopped if a peptic ulcer is diagnosed in a patient with active rheumatic disease. According to our experience, ulcer therapy can be carried through effectively in parallel with antiinflammatory treatment. Our data show that ranitidine and sucralfate have equal ulcer-healing efficacy and that there is no difference regarding the outcome of ulcer treatment in patients with either rheumatoid arthritis or osteoarthritis.

Thanks are expressed to Anna and Jakob Jakobsen's Legacy for financial support.

\section{References}

1 Sun DC, Roth SH, Mitchell CS, Englund DW. Upper gastrointestinal disease in rheumatoid arthritis. Am J Dig Dis 1974; 19: 405-10.

2 Silvoso GR, Ivey KJ, Butt JH, et al. Incidence of gastric lesions in patients with rheumatic disease on chronic aspirin therapy. Ann Intern Med 1979; 91: 517-20.

3 Caruso I, Bianchi PG. Gastroscopic evaluation of antiinflammatory agents. Br Med J 1980; 280: 75-8.

4 Collier DSJ, Pain JA. Non-steroidal anti-inflammatory drugs and peptic ulcer perforation. Gut 1985; 26: 359-63.

5 Cooke AR. Drug damage to the gastroduodenum. In: Sleisinger MH, Fordtran JS, eds. Gastrointestinal disease. 2nd ed. Philadelphia: WB Saunders, 1978: 807-26.

6 Kurata JH, Elashoff JD, Grossmann MI. Inadequacy of the literature on the relationship between drugs, ulcers, and gastrointestinal bleeding. Gastroenterology 1982; 82: 373-6.

7 Rees WD, Turnberg LA. Reappraisal of the effects of aspirin on the stomach. Lancet 1980; ii: 410-3.

8 Somerville K, Faulkner G, Langman M. Non-steroidal anti-inflammatory drugs and bleeding peptic ulcer. Lancet 1986; i: 462-4.

9 Cooker JR, Cotton PB, Boyle AC, Kinsella P. Cimetidine for peptic ulcer in patients with arthritis. Ann Rheum Dis 1980; 39: 275-8.

10 O'Laughlin JC, Silvoso GR, Ivey KJ. Resistance to medical therapy of gastric ulcers in rheumatic disease patients taking aspirin: A double-blind study with cimetidine and follow-up. Dig Dis Sci 1982; 27: 976-80.

11 Porro GB, Petrillo M, Lezzaroni M, Caruso I, Montrone F, Fumagalli M. Ranitidine in the treatment of anti-inflammatory drugs induced gastric lesions. Proceedings of the world Congress of Gastroenterology, Stockholm. [Abstract]. Scand J Gastroenterol. 1982; 17: suppl 78: 631 .

12 Peterson WL, Elashoff J. Placebos in clinical trials of duodenal ulcer: The end of an era? Gastroenterology 1980; 79: 585-8.

13 Lanza FL. Endoscopic studies of gastric and duodenal injury after the use of ibuprofen, aspirin, and other nonsteroidal anti-inflammatory agents. Am J Med 1984; 77: 19-24.

14 Brogden RN, Heel RC, Speight TM, Avery GS. Sucralfate: A review of its pharmacodynamic properties and therapeutic use in peptic ulcer disease. Drugs 1984; 27: 194-209.

15 Zeldis JB, Friedman LS, Isselbacher KJ. Ranitidine: A new $\mathrm{H}_{2}$-receptor antagonist. $N$ Engl J Med 1983; 309: 1368-73.

16 Thomas JM, Misiewicz G. Histamine $\mathbf{H}_{2}$-receptor antagonists in the short- and long-term treatment of duodenal ulcer. In: Isenberg JI, Johansson C, eds. Clinics in gastroenterology. Vol 13. Peptic ulcer disease. London: WB Saunders, 1984: 501-41. 